\title{
Çölyak hastalarında ve sağlıklı çocuklarda laktoz malabsorbsiyonu
}

\author{
Lactose malabsorption in children with celiac disease and healthy children
}

\author{
Atakan Comba, Fatma Demirbaş, Esra Eren, Gönül Çaltepe, Özlem Yüce, Ayhan Gazi Kalaycı
}

Gönderilme tarihi:25.02.2019

Kabul tarihi:14.05.2019

\section{Özet}

Amaç:Laktoz malabsorbsiyonu, doğuştan, primer veya sekonder olarak ortaya çıkabilir. Çölyak hastalığı, sekonder laktoz malabsorbsiyona neden olan bir hastalıktır. Bu çalışmada, çölyak hastası çocuklar ile sağlıklı çocuklarda laktoz hidrojen nefes testi ile laktoz malabsorbsiyon sıklığının belirlenmesi amaçlanmıştır.

Gereç ve Yöntem:Çalışmaya, 64 çölyak hastası ve 52 sağlıklı çocuk dahil edildi. Çölyak hastaları yeni tanı alanlar ve takipli çölyak hastaları olarak iki gruba ayrıldı. Takipli çölyak hastaları tedaviye (glutensiz diyete) tam uyumlu olanlar ve tedaviye uyumsuz olanlar olarak iki grupta incelendi. Laktoz hidrojen nefes testi 0-500 ppm hidrojen seviyesini algılayabilen ve 1 ppm düzeyinde duyarlı gaz analiz cihazı kullanılarak yapıldı.

Bulgular: Çocukların ortalama yaşı 10,4 $\pm 4,5$ yıldı. Çölyak hastalarının 16'sı yeni tanılı, 48'i takipli idi. Takipli çölyakların 24'ü (\%50) glutensiz diyete tam uyumluydu. Yeni tanı çölyak hastalarının \%62,5'inde, glutensiz diyete uyumsuz olanların \%54,2'sinde, glutensiz diyete tam uyumluların \%33,3'ünde, sağlıklı çocukların ise \%19,2'sinde laktoz hidrojen nefes testi pozitifti. Yeni tanılı ve glutensiz diyete uymayan çölyak hastalarının laktoz hidrojen nefes testi pozitiflik oranı (sırasıyla, \%62,5; \%54,2), sağlıklı çocuklardan $(\% 19,2)$ anlamlı olarak yüksekti (sırasıyla, $p=0,002$ ve $p=0,003$ ). Hem çölyak hastalarında hem de sağlıklı çocuklarda, laktoz hidrojen nefes testi pozitif olanların beden kitle indeksi z skoru, negatif olan çocuklardan anlamlı olarak düşüktü ( $p \& \mid t ; 0,001, p=0,041 ;$ sırasıyla).

Sonuç: Çalışmada, çölyak serolojisi pozitif olan hastalarda laktoz hidrojen nefes testi pozitifliği anlamlı olarak yüksek bulundu. Çölyak hastalığında laktoz hidrojen nefes testi ile laktoz malabsorbsiyon sıklığı ve mukozal hasar indirekt olarak saptanabilir. Laktoz malabsorbsiyonu, beden kitle indeksi düşük olan çocuklarda daha sık görülmektedir.

Anahtar Kelimeler: Çocuk, çölyak hastalığı, hidrojen nefes testi, laktoz malabsorbsiyonu.

Comba A, Demirbaş F, Eren E, Çaltepe G, Yüce Ö, Kalaycı AG. Çölyak hastalarında ve sağlıklı çocuklarda laktoz malabsorbsiyonu. Pam Tıp Derg 2019;12:321-328.

\begin{abstract}
Purpose:Lactose malabsorption (LM) can be congenital, primary, or secondary. Celiac disease (CD) is a secondary cause of lactose malabsorption. This study aimed to determine lactose malabsorption frequency using a lactose hydrogen breath test (LHBT) in children with celiac disease and healthy children.

Materials and Methods:The study included 64 children with CD and 52 healthy controls. Celiac patients were divided into groups as newly diagnosed and followed celiac patients. The latter were divided into groups as compliance or noncompliance with gluten-free diet (GFD). LHBT was performed using a gas analyser with a 1-ppm sensor sensitivity of hydrogen levels of $0-500 \mathrm{ppm}$.

Results: Mean age of the children was $10.4 \pm 4.5$ years. Sixteen of the patients had newly diagnosed celiac disease, and $24(50 \%)$ were compliant with GFD. LHBT results were positive in $62.5 \%$ of the newly diagnosed CD patients, $33.3 \%$ of those compliant with GFD, $54.2 \%$ of those non-compliant with GFD, and $19.2 \%$ of controls. A significantly higher proportion of newly diagnosed CD (62.5\%) and non-compliant with GFD (54.2\%) had positive LHBT results than controls (19.2\%) ( $p=0.002$ and $p=0.003$, respectively). The body mass index $z$ scores of the children with LHBT positivity were significantly lower than others in both healthy children and children with CD ( $p \& \mid t ; 0.001, p=0.041$, respectively).
\end{abstract}

Atakan Comba, Yandal asistan, Ondokuz Mayıs Üniversitesi Tıp Fakültesi, Çocuk Gastroenteroloji, Hepatoloji Beslenme Anabilim Dalı, SAMSUN, e-posta: adcomba@gmail.com (orcid.org/0000-0002-8576-9550)

Fatma Demirbaş, Yandal asistan, Ondokuz Mayıs Üniversitesi Tıp Fakültesi, Çocuk Gastroenteroloji, Hepatoloji Beslenme Anabilim Dalı, SAMSUN, e-posta: fatmademirbas81@hotmail.com (https://orcid.org/0000-0003-1788-2559)

Esra Eren, Yandal asistan, Ondokuz Mayıs Üniversitesi Tıp Fakültesi, Çocuk Gastroenteroloji, Hepatoloji Beslenme Anabilim Dalı, SAMSUN, e-posta: esraeah@hotmail.com (orcid.org/0000-0001-7506-4672)

Gönül Çaltepe, Doç. Dr. Ondokuz Mayıs Üniversitesi Tıp Fakültesi, Çocuk Gastroenteroloji, Hepatoloji Beslenme Anabilim Dalı, SAMSUN, e-posta: caltepeg@gmail.com (orcid.org/0000-0001-8525-6352)

Özlem Yüce, Yandal asistan, Ondokuz Mayıs Üniversitesi Tıp Fakültesi, Çocuk Gastroenteroloji, Hepatoloji Beslenme Anabilim Dalı, SAMSUN, e-posta: kirmemisozlem@gmail.com (https://orcid.org/0000-0002-7051-9065)

Ayhan Gazi Kalaycı, Prof. Dr. Ondokuz Mayıs Üniversitesi Tıp Fakültesi, Çocuk Gastroenteroloji, Hepatoloji Beslenme Anabilim Dalı, SAMSUN, e-posta: ayhangk@omu.edu.tr https://orcid.org/0000-0003-2104-6801 
Conclusion:In our study, the frequency of LHBT positivity was significantly higher in celiac patients with positive celiac serology.LHBT identified mucosal damage as indirect in celiac disease. Lactose malabsorption is more common in children who have low body mass index.

Key Words: Child, celiac disease, hydrogen breath test, lactose malabsorption.

Comba A, Demirbaş F, Eren E, Çaltepe G, Yüce Ö, Kalaycı AG. Lactose malabsorption in children with celiac disease and healthy children. Pam Med J 2019;12:321-328.

\section{Giriş}

Çölyak hastalığı, genetik olarak yatkınlığı olan bireylerde, diyetteki glutene karşı kalıcı duyarlılık sonucu gelişen, bağırsak ve bağırsak dışı bulgularla seyreden, otoimmün, sistemik bir hastalıktır [1]. Dünya genelinde \%0,5-1 sıklıkta görülmektedir. Hastalık tipik, atipik, sessiz ve latent formlarda görülebilir [2]. Tipik çölyak hastalığı, 6-24 aylık çocuklarda diyete gluten girdikten sonra başlayan kronik ishal, karın şişliği ve kilo kaybı ile bulgu veren bir hastalıktır [3]. Çölyak hastalığının günümüzde tek tedavisi ömür boyu glutensiz diyet (GD)'tir [4]. Tedavi edilmeyen çölyak hastalarında mukozal laktaz aktivitesinin sıklıkla azaldığı ve laktoz malabsorbsiyonu (LM) geliştiği bilinmektedir [5].

Laktoz, glukoz ve galaktoz monosakkaritlerinden oluşan ve sadece memelilerin sütünde bulunan bir primer karbonhidrattır [6]. Laktoz'un absorbsiyonu için ince bağırsak fırçamsı kenar enzimi olan ve villusların tepesinde bulunan 2 monosakkarit arasındaki bağı ayıran lactase-phlorizin hydrolase (çoğunlukla laktaz olarak bilinir) enzimi gereklidir [7]. Parçalanma sonrası bu monosakkaritler, enterositler tarafından kan akımına absorbe edilir [8].

Insanların \%70'inde etnik ve yaş gibi faktörlere ilişkili olarak laktaz enziminde zamanla azalma görülür [9]. Bu durum primer laktaz eksikliği veya adult-type hypolactasia (lactase-nonpersistence) olarak adlandırılır [7, 9]. Laktoz malabsorbsiyonu, sindirilen laktoz miktarı ile laktaz enzimi arasındaki dengesizlik nedeniyle oluşan fizyolojik bir problem olup, asemptomatik bir durumdur [7]. Laktoz veya laktoz içeren gıdaların sindiriminden sonra, karın ağrısı, şişkinlik ve gaz ve ishal gibi semptomların bir veya fazlasının oluşmasına laktoz intoleransı denir [7]. Sekonder laktaz eksikliği infeksiyöz enterokolit, inek sütü protein allerjisi, persistan diyare, çölyak hastalığı ve crohn hastalığı gibi ince bağırsak hasarı yapan hastalıklardan kaynaklanan laktaz eksikliğidir [6, 8]. Sindirilmeden kolona geçen laktoz, bakteriler tarafından hidrolize edilir ve karbondioksit, hidrojen, metan ve kısa zincirli yağ asitleri (propiyonik asit ve butirik asit) üretilir [10]. Normalde insan hücreleri hidrojen ve metan üretmezler. Bakteriler tarafından üretilen hidrojen ve metan difüzyon yoluyla kan dolaşımına geçer ve nefes ile solunumdan atııı [11].

Laktoz hidrojen nefes testi (LHNT) LM sonucu kana geçen ve nefesle atılan hidrojeni kromotografi ile kantitatif olarak saptayan bir yöntemdir [11]. Azalmış laktaz aktivitesi, ince bağırsak mukozal hasarının hassas bir göstergesidir. Bu nedenle çölyak hastalarında LHNT ile LM durumu incelenerek mukozal hasar varlığı değerlendirilebilir [5].

$\mathrm{Bu}$ çalışmanın amacı, LHNT ile çölyak hastaları ve sağlıklı çocuklarda LM sıkığını saptamak ve etkileyen faktörlerini belirlemektir. Diğer amacımız ise çölyak hastalarında GD'e uyumun LM üzerindeki etkisini araştırmaktır.

\section{Gereç ve yöntem}

Çalışma, Ondokuz Mayıs Üniversitesi Hastanesi Çocuk Gastroenteroloji Hepatoloji ve Beslenme Bilim Dalı'nda yapıldı. Çalışmaya 64 çölyak 52 sağlıklı kontrol olmak üzere toplam 116 çocuk dahil edildi.

Çölyak hastalığı tanısı için, serum doku transglutaminaz IgA ve antiendomisium IgA ve serum IgA düzeyleri ölçüldü. Selektif IgA eksikliği olan hastalarda dokutransglutaminaz IgG antikor düzeyi ölçüldü. Doku transglutaminaz IgA ve IgG (Euroimmun, Germany) mikro ELISA ile antiendomisium antikoru (Euroimmun, Germany) indirekt immunfloresan yöntemi ile çalışıldı. Antikorları pozitif bulunan hastalara endoskopi (Olympus, GIF Q240Z, Japan) yapıldı, Duodenum 2. kısım ve bulbustan çoklu biyopsiler alındı. Biyopsilerde, histopatolojik 
sınıflandırması için Modifiye Marsh (Oberhuber) klasifikasyonu kullanıldı [12].

Çölyak hastaları başvuru bulgularına göre tipik ve atipik olarak sınıflandırıldı. Hastaların sosyodemografik özellikleri, antopometrik ölçümleri ve laboratuar değerleri kaydedildi. Hastalar, yeni tanı alanlar ve takipli hastalar olarak iki gruba ayrıldı.

Yeni tanı çölyak hastaları, henüz tanı almış olan ve glutensiz diyetin ilk haftasında olan çocuklardan oluşturuldu. Takipli çölyak hastaları ise en az bir yıldır tanısı olan ve düzenli takipteki hastalardan oluştu.

Takipli çölyak hastaları tedaviye (glutensiz diyete) tam uyumlu olanlar ve tedaviye uyumsuzlar olarak iki gruba ayrıldı. Kontrollerde çocukların diyet uyum öyküleri de esas alınarak, serum çölyak antikoru seviyesi negatif olanlar GD'ye tam uyumlu, antikor seviyesi pozitif olanlar ise GD'ye uyumsuz olarak kabul edildi.

Sağlıklı çocuklardan oluşan kontrol grubu, çölyak hastaları ile yaş ve cinsiyet uyumlu kreş ve okul çocuklarından seçildi.

Hidrojen nefes testi 0-500 ppm arası hidrojen düzeyi ölçebilen sensor hassasiyeti $1 \mathrm{ppm}$ olan bir gaz analizörü (Bedfont Gastro+Gastrolyzer, Bedfont Scientific Ltd, ME13QX, England) ile yapıldı. Çocuklara, hidrojen nefes testinden en az 3 gün öncesinde karbonhidrattan fakir diyet verildi. Test öncesi 4 hafta içerisinde antibiyotik, probiyotik ve laksatif tedavisi kullanılmasına izin verilmedi, kullananların testleri ertelendi. Koopore olamayan çocuklar, inflamatuar bağırsak hastalığı olanlar, bakteriyel aşırı çoğalma ve parazitik enfeksiyonu olan çocuklar çalışmadan dışlandı. Hem hasta hem de kontrol grubunun 12 saat açlığı takiben bazal nefes değerleri elde edildi. Bazal hidrojen ölçümü 10 ppm'in üstü olanlar çalışmaya alınmadı. Ölçüm sonrası $2 \mathrm{gr} / \mathrm{kg}$ (maksimum $25 \mathrm{gr}$ ) laktoz içirilerek 180 dakika boyunca her 15 dakikada bir nefeste hidrojen düzeyi ölçümü yapıldı. Ölçüm boyunca bazal değerden iki kez 20 ppm üzeri değer elde edilmesi pozitif kabul edildi [7, 13, 14]. Çalışma için, Ondokuz Mayıs Üniversitesi Klinik Araştırmalar Etik Kurul izni ve çocuk ile anne-babalarından, bilgilendirilmiş gönüllü olur formu alındı.

\section{İstatistiksel Analiz}

Normal dağılım gösteren veriler ortalama \pm standart deviasyon; normal dağılım göstermeyen veriler ortanca (en küçük-en büyük) olarak verildi. Normal dağılım gösteren bağımsız ikili gruplar $t$ testi ile ikiden fazla grup değişkeni olanlar One-Way ANOVA ile karşılaştırıldı, ikili karşılaştırmalarda Tukey testi kullanıldı. Normal dağıış göstermeyen verilerde ikili gruplar Mann-Whitney $U$ testi ile ikiden fazla değişkenli gruplar Kruskall-Wallis testi ile karşılaştırıldı ve bonferroni düzeltmesi yapıldı. Nitel veriler için yüzdeler karşılaştırılırken pearson ki-kare testi ve $\mathrm{z}$ testi yapıldı. $P$ değerinin 0,05 'ten küçük olması anlamlı kabul edildi.

\section{Bulgular}

Çalışmaya, 64 (\%55,2) çölyak hastası 52 $(\% 44,8)$ sağlıklı çocuk olmak üzere toplam 116 çocuk alındı (Şekil 1). Yaşları ortalaması

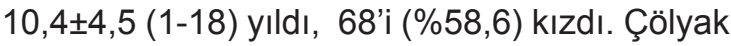
hastalarının 16'sı (\%25) yeni tanı çölyak, 48'i (\%75) de takipli çölyak hastası idi. Takipli çölyak hastalarının takip süreleri $57 \pm 35$ (12-139) aydı, 24'ü (\%50) GD'ye tam uyuyordu (Tablo 1). Çölyak hastaların biyopsilerinde 19'u (\%29,7) Marsh 3a, 27'si (\%42,3) 3b, 18'i (\%28) 3c idi. Çölyak hastalarının yaş ortalaması $(10,7 \pm 4$ yıl) ile kontrol grubunun yaş ortalaması $(10,1 \pm 4 \mathrm{yIl})$ benzerdi $(p=0,503)$.

Yeni tanı çölyak hastalarında $10(\% 62,5)$ hasta; GD'ye tam uyumlu grupta $8(\% 33,3)$ hasta; GD'ye uymayan grupta $13(\% 54,2)$ hasta, kontrol grubunda ise $10(\% 19,2)$ çocukta LHNT pozitif saptandı (Tablo 2 ).

Hem yeni tanı hem de diyetine uymayan çölyak hastalarında LHNT pozitiflik oranı kontrol grubuna göre anlamlı olarak yüksekti (sırasıyla, $p=0,002$ ve $p=0,003$ ). Glutensiz diyete uyumlu grup ile GD'ye uyumsuz grup karşılaştırıldığında, diyete uyumsuz olan grupta LHNT pozitiflik oranı belirgin olarak yüksek olmakla birlikte istatistiksel anlamlı fark bulunmadı $(p=0,146)$. Çölyak antikoru pozitif olan hastaların (yeni tanı + GD'ye uyumsuz olanlar) LHNT pozitiflik oranı $(\% 57,5)$ antikor negatif hastalardan (GD'ye tam uyumlu) $(\% 33,3)$ anlamlı olarak yüksekti $(p=0,001)$. 


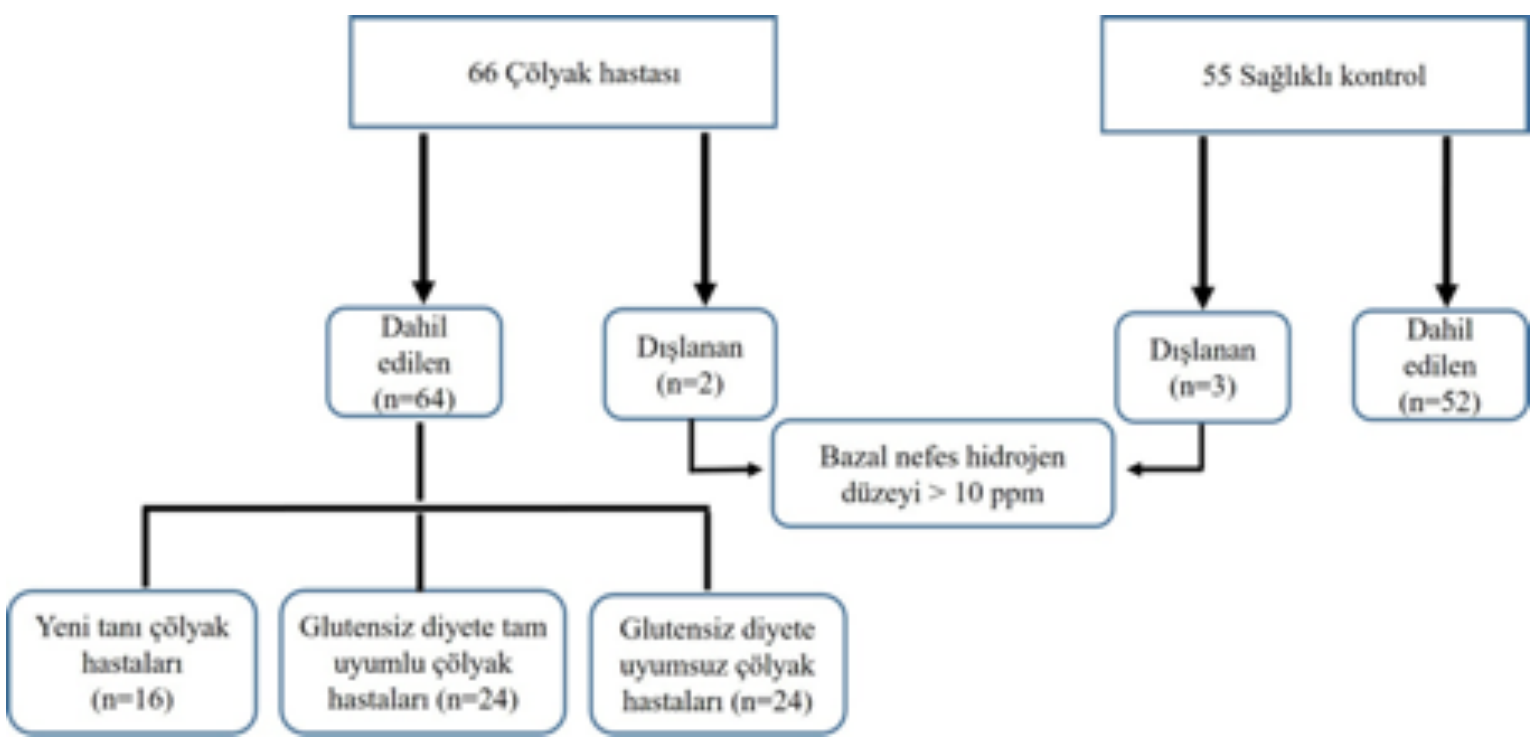

Şekil 1. Çalışma akış şeması.

Tablo 1. Çölyak hastaları ve sağlıklı çocukların genel özellikleri.

Cinsiyet

\begin{tabular}{|c|c|c|c|}
\hline & & Yaş (yıl) & \\
\hline Gruplar & $\mathrm{n}$ & OrtıSD (en küçük-en büyük) & $(\mathrm{n}, \%)$ \\
\hline
\end{tabular}

\begin{tabular}{ccccc}
\hline Çölyak hastaları (tümü) & 64 & $10,7 \pm 4,8(2-18)$ & $39(\% 60,9)$ & $25(\% 39,1)$ \\
Yeni tanı çölyak hastaları & 16 & $7,1 \pm 5,3(2-17)$ & $11(\% 68,8)$ & $5(\% 31,2)$ \\
Takipli çölyak hastaları & 48 & $11 \pm 4(4-18)$ & $28(\% 58,3)$ & $20(\% 41,7)$ \\
Tipik çölyak hastaları & 32 & $10,4 \pm 4,9(2-18)$ & $18(\% 56,3)$ & $14(\% 43,7)$ \\
Atipik çölyak hastaları & 32 & $10,9 \pm 4,9(2-18)$ & $21(\% 65,6)$ & $11(\% 34,4)$ \\
Glutensiz diyete tam & 24 & $11 \pm 4,3(4-18)$ & $14(\% 58,3)$ & $10(\% 41,7)$ \\
uyumlular & 24 & $12,7 \pm 3,5(4-18)$ & $14(\% 58,3)$ & $14(\% 41,7)$
\end{tabular}

Glutensiz diyete uyumsuzlar 
Tablo 2. Çocukların laktoz hidrojen nefes testi sonuçları.

\begin{tabular}{|c|c|c|c|c|}
\hline \multirow{3}{*}{ Gruplar } & \multirow{3}{*}{$n$} & Laktoz hic & testi sonucu & \multirow{3}{*}{$p$} \\
\hline & & \multicolumn{2}{|c|}{ ort $\pm S D, n(\%)$ veya ortanca (en küçük- en büyük) } & \\
\hline & & Pozitif (n, \%) & Negatif $(n, \%)$ & \\
\hline Yeni tanı çölyak hastaları & 16 & $10(\% 62,5)$ & $6(\% 37,5)$ & \\
\hline Sağlıklı kontrol & 52 & $10(\% 19,2)$ & $42(\% 80,8)$ & \\
\hline Glutensiz diyete tam uyanlar & 24 & $8(\% 33,3)$ & $16(\% 66,7)$ & $0,002^{\top}$ \\
\hline Glutensiz diyete uymayanlar & 24 & $13(\% 54,2)$ & $11(\% 45,8)$ & \\
\hline Yaş (yıl) & & $128 \pm 53$ & $132 \pm 57$ & $0,72^{\ddagger}$ \\
\hline $\mathrm{K} ı \mathrm{z}$ & 68 & $29(\% 42,6)$ & $39(\% 57,4)$ & \\
\hline Erkek & 48 & $12(\% 25)$ & $36(\% 75)$ & $0,050^{+}$ \\
\hline
\end{tabular}

† Ki-kare test; $\ddagger$ Mann-Whitney $U$ test

Çocukların genel özellikleri ile LHNT sonuçları arasındaki ilişki değerlendirildiğinde, yaş, cinsiyet, boy, boy z skoru ile arasında istatistiksel açıdan anlamlı bir farklılık saptanmadı.

Hem sağlıklı çocuklarda hem de çölyak hastalarında LHNT pozitif olan çocukların beden kitle indeksi (BKI) z skoru [sırasıyla, -0,9 (-3,5;$0,1)$ ve $-0,87(-2,4 ; 1,6)]$ negatif olan çocuklardan [ sırasıyla, $0,06(-2 ; 3),-0,33(-2 ; 1,6)]$ anlamlı olarak düşüktü (sırasıyla, $p<0,001, p=0,004$ ). (Tablo 3).

\section{Tartışma}

Çölyak hastalığı, genetik etkenlerin oluşumunda rol oynadığı buğday, arpa ve çavdardaki gluten tarafından indüklenen ince bağırsaklarda kronik inflamasyonla giden sistemik bir hastalıktır. Bu inflamasyon genel bir malabsorbsiyona neden olmaktadır. Yapılan çalışmalarda çölyak hastalarında plazma aminoasitlerinin düzeyinin değiştiği ve sağlıklı çocuklardan farklı olduğu belirlenmiştir [15]. Intestinal inflamasyon ayrıca duodenum ve jejunumda laktaz enziminde aktivite azalması ile sonuçlanır [1]. Bu histolojik değişim LM'ye neden olur ve LM nefeste hidrojen atılımının ölçümü ile saptanabilir [16].

Laktaz, ince bağırsak fırçamsı kenarlarında bulunan ve laktoz sindirimi için gerekli olan ve lactase-phlorozin hydrolase (LPH) için sıklıkla kullanılan bir terimdir. Human LPH, 2. kromozomun uzun kolunda lokalize olan LCT geni tarafından kodlanır. Laktaz nonpersistans veya adult-tip hipolaktazya (MIM223100) tamamlayıcı beslenmeye geçiş sırasında laktaz aktivitesi azalmasının sık görülen kalıtımsal bir nedenidir [17].

Laktoz malabsorbsiyonu ve intoleransı tanısında ilk olarak ince bağırsak biyopsisinde laktaz enzim aktivitesinin ölçümü ve laktoz tolerans testi kullanılmıştır. Ancak ilki invaziv olması ve diğeri de düşük duyarlılığı nedeniyle günümüzde çok kullanılmamaktadır. Normalde laktoz intoleransı tanısı çocuklarda iyi bir klinik öykü ile konabilir ve laktozsuz diyet ile tanı doğrulanabilir [7, 9]. Günümüzde LM tanısında LHNT ve genetik testler daha öncelikli olarak kullanılmaktadır [6, 8]. Hızlı ve non invaziv olan LHNT'nin sensitivitesi \%70-100, spesifitesi $\% 100$ olarak belirtilmiştir [10].

LHNT ile çölyak hastalığında LM sıklığı ile mukoza hasarı saptanabilir ayrıca tekrarlayan testlerle mukozanın iyileşme süresi değerlendirilebilir. Murphy ve ark. [5] LHNT ile mukozal hasarı değerlendirdikleri bir çalışmada, yeni tanı çocuk çölyak hastalarında \%48 oranında LHNT pozitifliği saptamışlar; hastaların \%86'sında dört haftada, \%14'ünde ise sekiz haftada mukozada düzelme saptadıklarını bildirmişlerdir. Oysa yetişkinlerde yapılan bir çalışmada, hastaların \%6,7'sinde 6. ayda diğerlerinde ise 12. ayda laktoz malabsorbsiyonunun düzeldiği rapor edilmiştir [18].

Ojetti ve ark. [16] LHBT ile laktoz intoleransı saptanan yetişkinlerde çölyak hastalığı sıklığını araştırdıkları bir çalışmada, hastaların 
Tablo 3. Laktoz hidrojen nefes testi sonuçları ile ilişkili faktörler.

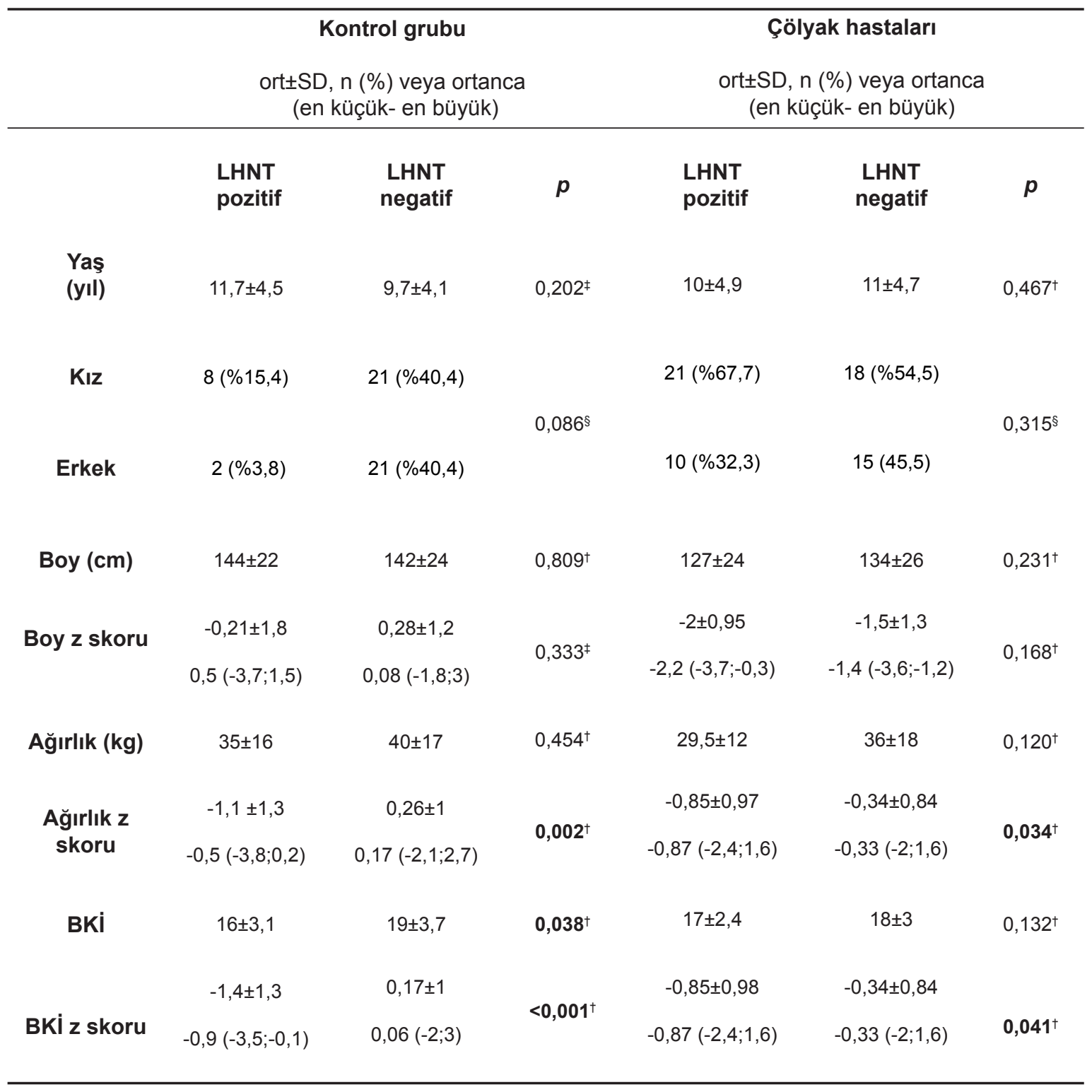

† t test; $\ddagger$ Mann-Whitney $U$ test; $\S$ ki-kare test; BKi, beden kitle indeksi; LHNT, laktoz hidrojen nefes testi

\%24'ünde, kontrol grubunun da \%2'sinde çölyak hastalığı saptamışlardır. Yetişkinlerde yapılan iki farklı çalışmada ise, GD'ye cevap vermeyen çölyak hastalarında LHNT ile laktoz intoleransı olduğu gösterilmiştir [19, 20]. Benzer olarak Leffler ve ark. [21] erişkinlerde yaptığı bir çalışmada, GD'ye rağmen persistan şikayeti olan hastaların \%8'inde LHBT'de pozitiflik olduğunu bildirmişlerdir.

Çalışmamızda yeni tanı çölyak hastalarının $\% 62,5$ 'inde takipli çölyak hastalarında ise $\% 43,75$ LHNT pozitifliği vardı. Yeni tanı çölyak hastalarında ve GD'ye uymayan çölyak hastalarında LM sıklığı, sağlıklı gruba göre anlamlı olarak yüksekti. GD'ye tam uyumlu çölyaklarda yeni tanı çölyak hastalarına göre LM sıklığı daha düşük olmakla birlikte anlamlı bir fark görülmedi.

Dünya nüfusunun yaklaşık \%70'inde primer laktaz eksikliği vardır. Primer laktaz eksikliğinin Avrupa'da \%25, Akdeniz bölgesinde \%60-100 arasında olduğu belirtilmiştir [10]. Meksika'da Moran ve ark. [22] çocuklarda yaptığı bir çalışmada laktoz malabsorbsiyon sıklığını \%31 olarak bulmuş; başka bir çalışmada ise ilk 5 yaştaki çocuklarda laktoz malabsorbsiyon sıklığı \%21,3 bulunmuştur [23]. Harvey ve ark. [24] tarafından yapılan bir metaanalizde $1-5$ yaş arası çocuklarda laktoz malabsobsiyon sıklı̆̆ $\% 0$ ile $\% 17,9$ arasında bildirilmektedir. Bizim 
çalışmamızda ise sağlıklı çocuklarda LM sıklığı $\% 19,2$ olarak bulundu.

Laktaz ekspresyonunda azalma toplumlara göre değişmekle birlikte genelde çocukluk çağı ya da geç adolesan döneminde tamamlanır $[7,8]$. İspanyol, Asyalı ve siyah çocukların \%20'sinde 5 yaşında önce laktoz intoleransı ya da malabsorbsiyon tanımlanırken, beyaz çocuklarda genellikle beş yaşından önce gelişmez [7, 8]. Çalışmamızda çocukların yaşları ile LHNT arasına bir ilişki saptanmadı. Laktaz aktivitesinin kayıp oranı etnisiteye göre değişmekle birlikte, kaybın zamanlamasındaki değişimin fizyolojik açıklaması bilinmemektedir [9]. Önceki çalışmalarda, malnütrisyon ile LM arasındaki bir ilişki olduğu gösterilmiştir [25, 26]. Çalışmamızda da benzer olarak hem sağlıklı çocuklarda hem de çölyak hastalarında BKI z skoru düşük olanlarda LM sıklığı daha yüksek bulundu.

LHNT ile LM tanısında \%2,5 ile \%15 arasında yanlış negatif sonuç bildirilmiştir [11]. Hidrojen nefes testi, hidrojen üreten bakteri varlığına bağlıdır, fakat bazı insanlarda kolonik flora hidrojen üretmez. Non-H2 üreticilerde baskın kolonik bakteriler metan üreten bakterileridir ki bunun sıklığı \%3-25 olarak bulunmuştur [27, 28].

Bu çalışmanın kısıtlılığı, hastalarda laktaz eksikliği tanısında kesin tanı göstergesi olan genetik testlerin yapılamamasıdır. Ayrıca, non-H2 üreten çocukları saptamak için de metan nefes testi yapılamamıştır.

Sonuç olarak, çalışmamızda çölyak hastalarında LHNT'nin ince bağırsak mukoza hasarını göstermede etkili olduğu, ancak GD'ye uyumu ayırmada etkili olmadığı saptanmıştır. Ayrıca beden kitle indeksi düşük olan çocuklarda LM sıklığının daha fazla olduğu gösterilmiştir.

Çıkar İlişkisi: Yazarlar, herhangi bir çıkar çatışması olmadığını beyan ederler.

\section{Kaynaklar}

1. Guandalini S, Setty M. Celiac disease. Curr Opin Gastroenterol 2008;24:707-712. https://doi. org/10.1097/MOG.0b013e32830f4527

2. Kang JY, Kang AHY, Green A, Gwee KA, Ho KY. Systematic review: Worldwide variation in the frequency of celiac disease and changes over time. Aliment Pharmacol Ther 2013;38:226-245. https://doi. org/10.1111/apt.12373
3. Lionetti E, Catassi C. New clues in celiac disease epidemiology, pathogenesis, clinical manifestations, and treatment. Int Rev Immunol 2011;30:219-231. https://doi.org/10.3109/08830185.2011.602443

4. Jadresin O, Misak Z, Sanja K, Sonicki Z, Zizić V. Compliance with gluten-free diet in children with coeliac disease J. Pediatr Gastroenterol Nutr 2008;47:344348. https://doi.org/10.1097/MPG.0b013e31816f856b

5. Murphy MS, Sood M, Johnson T. Use of the lactose $\mathrm{H} 2$ breath test to monitor mucosal healing in celiac disease. Acta Paediatr 2002;91:141-144.

6. Mattar R, de Campos Mazo DF, Carrilho FJ. Lactose intolerance: diagnosis, genetic, and clinical factors. Clin Exp Gastroenterol 2012;5:113-121. https://doi. org/10.2147/CEG.S32368

7. Heyman MB. Lactose intolerance in infants, children, and adolescents. Pediatrics 2006;118:1279-1286. https://doi.org/10.1542/peds.2006-1721

8. Lomer MCE, Parkes GC, Sanderson JD. Review article: lactose intolerance in clinical practice-myths and realities. Aliment Pharmacol Ther 2008;27:93-103. https://doi.org/10.1111/j.13652036.2007.03557.x

9. Castiglione F, Di Girolamo E, Ciacci C, et al. Lactose malabsorption: Clinical or breath test diagnosis? E Spen Eur E J Clin Nutr Metab 2008;3:e316-e320. https://doi.org/10.1016/j.eclnm.2008.07.018

10. Vandenplas Y. Lactose intolerance. Asia Pac J Clin Nutr 2015;24:9-13. https://doi.org/10.6133/apjcn.2015.24. s1.02

11. Däbritz J, Mühlbauer M, Domagk D, et al. Significance of hydrogen breath tests in children with suspected carbohydrate malabsorption. BMC Pediatr 2014;14:19. https://doi.org/10.1186/1471-2431-14-59

12. Oberhuber G, Granditsch G, Vogelsang H. The histopathology of coeliac disease: time for a standardized report scheme for pathologists. Eur J Gastroenterol Hepatol 1999;11:1185-1194.

13. Gijsbers CFM, Kneepkens CMF, Büller HA. Lactose and fructose malabsorption in children with recurrent abdominal pain: results of double-blinded testing. Acta Paediatr 2012;101:411-415. https://doi.org/10.1111/ j.1651-2227.2012.02721.x

14. Babu J, Kumar S, Babu P, Prasad JH, Ghoshal UC. Frequency of lactose malabsorption among healthy southern and northern Indian populations by genetic analysis and lactose hydrogen breath and tolerance tests. Am J Clin Nutr 2010;91:140-146. https://doi. org/10.3945/ajcn.2009.27946

15. Sevinc E, Himmet Akar H, Sevinc N, Arslan D, Can Sezgin G, Kendirci M. Amino acid levels in children with celiac disease. Nutr Hosp 2015;32:139-143. 
16. Ojetti V, Nucera G, Migneco A, et al. High prevalence of celiac disease in patients with lactose intolerance. Digestion 2005;71:106-110. https://doi. org/10.1159/000084526

17. Kerber M, Oberkanins $C$, Kriegshäuser $G$, et al. Hydrogen breath testing versus LCT genotyping for the diagnosis of lactose intolerance: a matter of age? Clin Chim Acta 2007;383:91-96. https://doi.org/10.1016/j. cca.2007.04.028

18. Ojetti V, Gabrielli M, Migneco A, et al. Regression of lactose malabsorption in coeliac patients after receiving a gluten-free diet. Scand J Gastroenterol 2008;43:174177. https://doi.org/10.1080/00365520701676138

19. Tursi A, Brandimarte G, Giorgetti G. High prevalence of small intestinal bacterial overgrowth in celiac patients with persistence of gastrointestinal symptoms after gluten withdrawal. Am J Gastroenterol 2003;98:839843. https://doi.org/ 10.1111/j.1572-0241.2003.07379.x

20. Ghoshal UC, Ghoshal U, Misra A, Choudhuri G. Partially responsive celiac disease resulting from small intestinal bacterial overgrowth and lactose intolerance. BMC Gastroenterol 2004;4:1-6. https://doi. org/10.1186/1471-230X-4-10

21. Leffler DA, Dennis M, Hyett B, Kelly E, Schuppan D, Kelly CP. Etiologies and predictors of diagnosis in nonresponsive celiac disease. J Clin Gastroenterol Hepatol 2007;5:445-450. https://doi.org/10.1016/j. cgh.2006.12.006

22. Moran S, Mina A, Duque X, et al. Prevalence of lactose malabsorption in Mexican children: importance of measuring methane in expired air. Arch Med Res 2013;44:291-295. https://doi.org/10.1016/j. arcmed.2013.04.005

23. Hegar B, Widodo A. Lactose intolerance in Indonesian children. Asia Pac J Clin Nutr 2015;24:31-40. https://doi.org/10.6133/apjcn.2015.24. s1.06

24. Harvey L, Ludwig T, Hou AQ, et al. Prevalence, cause and diagnosis of lactose intolerance in children aged 1-5 years: a systematic review of 1995-2015 literature. Asia Pac J Clin Nutr 2018;27:29-46. https://doi. org/10.6133/apjcn.022017.05

25. Kvissberg MA, Dalvi PS, Kerac M, et al. Carbohydrate malabsorption in acutely malnourished children and infants: a systematic review. Nutr Rev 2016;74:48-58. https://doi.org/10.1093/nutrit/nuv058

26. Nichols BL, Dudley MA, Nichols VN, et al. Effects of malnutrition on expression and activity of lactase in children. Gastroenterology 1997;112:742-751.

27. Braden B. Methods and functions: Breath tests. Best Pract Res Clin Gastroenterol 2009;23:337-352. https:// doi.org/10.1016/j.bpg.2009.02.014
28. Ruzsanyi V, Heinz-Erian $P$, Entenmann $A$, et al. Diagnosing lactose malabsorption in children: difficulties in interpreting hydrogen breath test results. J Breath Res 2016;10:016015. https://doi. org/10.1088/1752-7155/10/1/016015

Teşekkür: Çalışma sırasındaki destek ve yoğun gayretleri nedeniyle, Hemşire Nevin Kıroğlu ve Emine Çilingir'e çok teşekkür ederiz.

Bu çalışma için, Ondokuz Mayıs Üniversitesi Klinik Araştırmalar Etik Kurulu'ndan 28.02.2013 tarih ve 2013/231 sayı ile izin alınmıştır. 